\title{
Yenilikçi Trokoidal Frezelemenin Kesme Performansı Üzerinde Etkilerinin Araştırılması: Bir Derleme Çalışması
}

\author{
Investigation of the Effects of Innovative Trochoidal Milling on Cutting Performance: \\ A Review Study
}

\author{
Semih YÜKSEL ${ }^{1}{ }^{\mathbb{D}}$, Mustafa $A Y^{2}{ }^{\mathbb{D}}$ \\ ${ }^{1}$ Marmara Üniversitesi, Fen Bilimleri Enstitüsü, Makine Mühendisliği Bölümü, 34722, İstanbul, Türkiye \\ ${ }^{2}$ Marmara Üniversitesi, Teknoloji Fakültesi, Makine Mühendisliği Bölümü, 34722, İstanbul, Türkiye
}

Öz

Hızla gelişen küresel ekonomide üretim verimliliğini artırmak büyük bir önem taşımaktadır. Bu amaçla araştırmacılar işleme süreçlerinde, takım işleme sürelerini kısaltan ve takım ömrünü artıran, parametreler ve metotlar üzerine çalışmalarını yönlendirmişlerdir. Özellikle kalıpçılık, otomotiv, havacılık ve medikal sektörlerinde takım işleme sürelerini düşürmek için takım yolları ve işleme parametreleri büyük rol oynamaktadır. Bununla ilgili olarak birçok optimizasyon çalışmaları yapılmış, yapılan çalışmalar neticesinde üretim verimliliğinin sadece takım ve tezgâh kalitesinin iyileştirilmesi ile değil, parçaya göre en uygun takım yolunun seçilmesi ve üretilmesi ile de mümkün olduğu ispatlanmıştır. Son zamanlarda bu işleme sürelerini düşüren üretim verimliliğini artıran alternatif bir takım yolu olan trokoidal frezeleme gitgide popüler bir işleme yöntemi olarak ön plana çıkmaktadır. Trokoidal frezeleme kesilmesi zor ve zaman alan malzemelerin kolay işlenebilmesi için umut veren bir işleme teknolojisidir. Konvansiyonel frezeleme metoduna göre işlem süresini kısaltan bu yöntem araştırmacılar tarafindan tam anlamıyla anlaşılamamış ve araştırmaya açık bir alan olarak kalmıştır. Bu çalışmada, trokoidal frezeleme yönteminde yapılan araştırmalar neticesinde takımın yüksek kesim ve ilerlemesi ile uygun takım yolları araştırılmıştır. Araştırma neticesinde doğrusal kesme şartlarında işlemesi zor malzemelerin kesme esnasında takımda ve malzemede sıcaklık değerleri yükselttiği, talaşın malzeme üzerinden ayırma hızını yavaşlattığı, ayrıca yüksek kesme hızlarından ve ilerlemelerden kaynaklanan kesme kuvvetlerinin artmasına bağlı olarak takım aşınma hızının artığı ispatlanmıştır. Bu çalışmada, Trokoidal frezelemeye ait genel bilgi verilmiş, yakın zamanda yapılan çalışmalar değerlendirilmiş ve gelecekteki potansiyeli ve sağlayabileceği yararlar değerlendirilmiştir.

Anahtar Kelimeler: Trokoidal Frezeleme, Takım yolu, İşleme Süresi, Takım Aşınması.

\begin{abstract}
Increasing production efficiency is of great importance in the fast developing global economy. For this purpose, the researchers directed their studies on parameters and methods in their machining studies, which shorten the tooling times and increase the tool life. Tool paths and machining parameters play a major role in reducing tooling times, especially in the molding, automotive, aerospace and medical industries. Many optimization studies have been carried out in this regard, and as a result of the studies, production efficiency has been proved to be possible not only by improving the tool and machine quality, but also by choosing and producing the most suitable tool path according to the part. Trochoidal milling, which is an alternative tool way that has recently increased production efficiency, which has reduced these machining times, is becoming an increasingly popular machining method. Trochoidal milling is a promising machining technology for easy machining of difficult and time-consuming materials. This method, which shortens the processing time according to the conventional milling method, stands out as a field that is not fully understood by the researchers and is open to research. In this study, general information about Trochoidal milling is given and recent studies are evaluated and its future potential and po As a result of the research, it has been proved that the materials that are difficult to process under linear cutting conditions increase the temperature values in the tool and the material during cutting, the speed of separation of the sawdust from the material, and the tool wear speed increases accordingly as a result of the increase in cutting forces due to high cutting speeds and advances. In this study, general information about Trochoidal milling is given and recent studies are evaluated and its future potential and potential benefits are evaluated.
\end{abstract}

Keywords; Trochoidal Milling, Toolpath, Machining Time, Tool Wear 


\section{GİRIŞ̧}

Küresel ekonominin büyümesiyle birlikte üretim verimliliğinin önemi giderek artarak önemli bir noktaya ulaşmıştır. Bu artış üretimin her aşamasında verimli ve maliyet yönünden olumlu etki edecek üretim ve işleme süreçlerinin optimizasyonu ile ilgili çalışmalar yapan araştırmacıların sayısına yansımıştır. Araştırmacıların hedef noktalarından biri de frezeleme operasyonlarında işleme süresini düşüren, takım sarfiyatını azaltan, kaliteli ve verimli bir üretim gerçekleştirmektir. Özellikle üretimde bu verimliliğin artmasıyla, işlenmesi zor olan havacılık ve savunma sanayi parçalarındaki işleme süresi azaltılarak kalitenin artırılması önemli bir amaç haline gelmiştir. Frezede işleme süreçlerini düşürebilmek ve kaliteyi artırabilmek için kesme koşulları, takım yolları ve takımlar üzerine birçok çalışma yapılmıştır. Sayısal kodlar ile donatılmış yüksek dinamik takım tezgahlarının ortaya çıkmasıyla birlikte, yüksek hızlı frezeleme işlemiyle ilgili talepleri karşılamak için yeni tür stratejiler artmıştır [1]. $\mathrm{Bu}$ çalışmaların artması ile son zamanlarda cad-cam programlarının gelişmesi ile işleme süresini kısaltmak için alternatif takım yolları bulunmuştur. Yüksek ilerleme ve devir ile yüksek verimlilik sağlayan takım yollarından biri de trokoidal takım yoludur. Trokoidal frezeleme, kesilmesi zor malzemelerin yüksek verimli işlenmesi için umut verici bir teknolojidir [2]. Trokoidal frezeleme, azaltılmış kesme kuvveti yükü ve daha iyi ısı dağılımı sayesinde, kesici takım ömrünü önemli ölçüde uzatmaya yardımcı olduğundan kanal işlemek için iyi bir yöntemdir. Ayrıca trokoidal frezeleme, geleneksel dairesel frezelemeye göre toplam işleme süresi ve talaş kaldırma oranı tarafından daha üstündür [3]. Trokoidal frezeleme; takım aşınması başına malzeme kaldırma oranını artırarak malzeme kesme enerjisini azaltıp takım performansını iyileştirirken, aynı zamanda verimlilik maliyetiyle birlikte alternatif bir yol olarak ön plana çıkmaktadır. Takımın düşük radyal kesme kuvvetlerine ek olarak, trokoidal frezelemenin nikel bazlı süper alaşımlar gibi zor kesilen alaŞımların işlenmesinde arzu edilen bir takım yolu olmasını sağlamıştır [4]. Ayrıca trokoidal işlemede kesme kuvvetinin köşelerde ve dar yuvalarda takım aşınması üzerinde daha iyi kontrol sağladığ 1 ispatlanmıştır [5]. Trokoidal takım yolu ile ilgili yapılan çalışmalarda takım yolunun farklılığg ve kesme kuvvetlerinde farklı değerler alması sebebiyle araştırmacılar tarafindan tam anlamıyla anlaşılamamış ve bundan dolayı bu yöntemin daha derinden araştırılması gerekliliğine vurgulanmıştır. Trokoidal frezeleme sürecini daha iyi anlamak ve üretim senaryolarını optimize etmek için kesme kuvvetlerinin modellenmesi araştırmaları yapılmıştır. Takımın konvansiyonel kanal açma prosesi boyunca izlediği lineer yollar yerine, dairesel olan bir takım yolu takip ederek gerçekleştirdiği talaş kaldırma hareketine trokoidal frezeleme denmektedir [6]. Takım izlediği yol Şekil 1 de gösterilmiştir.

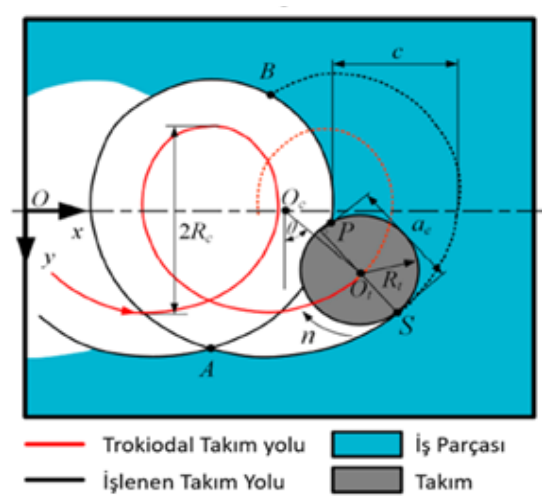

Şekil 1. Trokoidal frezelemenin geometrik modeli. Burada o_t, takım merkezi konumudur. Takım merkezinin mevcut dönme merkezi; dönme açısıdır, C, trokoidal basamaktır; R_c, trokoidal yarıçaptır; R_t takım yarıçapıdır ve a_e, c_u'nun mevcut radyal derinliğidir [2]

Trokoidal işleme metodunda, takım iş parçası ile hafif temas koşullarında (kesici takımın sadece takım ağzı teması) trokoidal bir yol izleyerek iş parçasının hassas bir şekilde dilimlenerek işlenmesini sağlar [7]. Bununla ilgili görsel Şekil-2 de gösterilmiştir.

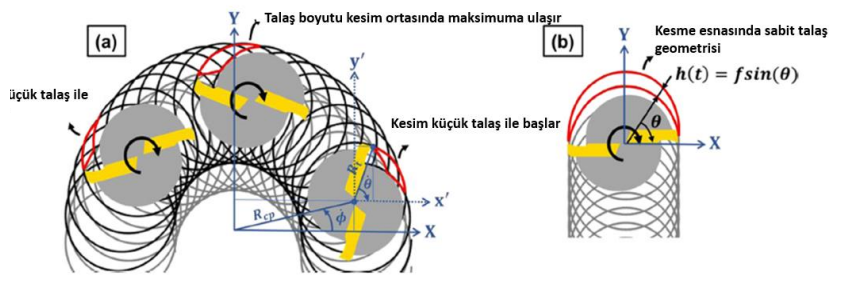

Şekil 2. (a) Trokoidal frezeleme ve (b) Geleneksel frezeleme için geometrik talaş şekli gösterimi [12]

Trokoidal frezelemede, konvansiyonel frezelemeye göre oluşan en büyük farklılıklardan birisi, takımın trokoidal hareketi boyunca kaldırılan talaşın kalınlığının sabit olmayışidır.

Kaldırılan talaşın ortalama kalınlığını veren formül aşağ1daki gibidir.

$\mathrm{h}_{\mathrm{m}}=\mathrm{f}_{\mathrm{z}} \frac{\sqrt{\mathrm{a}_{\mathrm{e}}}}{\mathrm{d}}$ olarak tanımlamaktadır. (1) 
$\mathrm{h}_{\mathrm{m}}=$ Ortalama Talaş Kalınlığı

$\mathrm{f}_{\mathrm{z}}=$ Maksimum Diş Başına İlerleme

$\mathrm{a}_{\mathrm{e}}=$ Yanal İlerleme $(\mathrm{mm})$

$\mathrm{d}=$ Takım Çapı $(\mathrm{mm})$

$\mathrm{Bu}$ formülün ve parametrelerin daha iyi anlaşılması için trokoidal frezeleme esnasında kaldırılan talaşın kalınlığını veren görüntü Şekil-3 de gösterilmiştir.

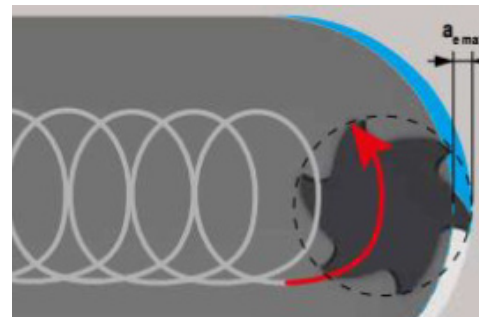

Şekil 3. Trokoidal frezeleme esnasında takımın ve kaldırılan talaşın üstten görüntüsü [6].

Trokoidal frezelemede kullanılan ve standart trokoidal frezeleme olarak CAM programlarında kabul edilen tam çembersel takım yolunun haricinde, yarım çember, çeyrek çember, elipsoidal gibi çembersel ve eliptik şekillerde değişik takım yolları üretilmiş, ancak ne yüzey pürüzlülüğü ya da takım aşınması bakımından, ne de takıma etkiyen kesme kuvvetleri bakımından standart çembersel (trokoidal) yol ile kıyaslanabilecek bir başarı elde etmemişlerdir. [6]

\section{LITERATÜR ARAŞTIRMASI}

Pleta ve Ark yapmış oldukları çalışmada, trokoidal frezeleme sürecini daha iyi anlamak ve üretim senaryolarını optimize etmek için kesme kuvvetlerinin modellenmesi çalışmasını yapmışlardır. Yapılan çalışmada kuvvet modellemesinin temeli, kesme kuvveti katsayıları ve kenar kuvvet katsayıları ile kesilmemiş talaş kalınlığı modellemesidir. Yazarlar Inconel 718 malzemesinin kesilmesi sonucunda ortaya çıkan değerler neticesinde bazı sonuçlara varmışlardır. Daha önce yazarlar tarafindan önerilen yeni bir kesilmemiş talaş kalınlığı modeli ile bu araştırma, model katsayılarının, maksimum kesme kuvveti ve takım aşınması gibi işleme çıktıları ile trokoidal yol parametreleriyle ilişkili olduklarını anladıklarını düşünülmektedir. Ayrıca, işleme parametreleri, minimum takım aşınması ve kesme kuvvetleri için optimal parametrelerin bulunduğu Taguchi yöntemini kullanarak takım ömrünün ve kesme gücünün iyileştirilmesi ile nasıl ilişkili oldukları araştırılmıştır. Trokoidal yolun, işleme tabi tutulan bölgeyle ilgili oldukları için işlenmiş numunelerin yüzeyi üzerindeki etkileri hem radyal hem de eksenel yönlerde araştırılmıştır. Yapılan çalışmada bazı giriş parametreler tanımlanmıştır. Bu giriş parametreler Tablo 1'de gösterilmiştir.
Tablo 1. Deney Giriş Parametreleri [8]

Trokoidal Takım Yolu Giriş Parametreleri

\begin{tabular}{lcccc}
\hline Takım Yolu Parametre & Sembol & Seviye1 & Seviye 2 & Seviye 3 \\
\hline Takım Devri (RPM) & $\dot{\theta}$ & 400 & 600 & 1200 \\
Döngüsel Oranı (rad/s) & $\dot{\phi}$ & 0.30 & 0.50 & 0.70 \\
Kesme Derinliği (mm) & $a_{p}$ & 0.50 & 1.00 & 0.75 \\
Diş başına ilerleme (mm) & $v_{\text {feed }}$ & 0.025 & 0.050 & 0.075 \\
\hline
\end{tabular}

Yapılan deneyler Taguchi deney metodu ile Kontrol faktörleri tanımlanmıştır. Yapılan deneyler bu kontrol parametreleri içerinde yer alan adı ile tanımlanmıştır. Bu kontrol parametreleri Tablo 2'de gösterilmiştir.

Tablo 2. Taguchi L9 için kontrol Faktör Parametreleri [8]

\begin{tabular}{lllll}
\hline T1 & 1 & 1 & 1 & 1 \\
T2 & 1 & 2 & 2 & 2 \\
T3 & 1 & 3 & 3 & 3 \\
T4 & 2 & 1 & 2 & 3 \\
T5 & 2 & 2 & 3 & 1 \\
T6 & 3 & 1 & 2 \\
T7 & 2 & 1 & 3 & 2 \\
T8 & 3 & 2 & 1 & 3 \\
T9 & 3 & 3 & 2 & 1 \\
\hline
\end{tabular}

Yapılan deneylerin sonuçları Şekil 4-5-6 ve 7'de gösterilmiştir."

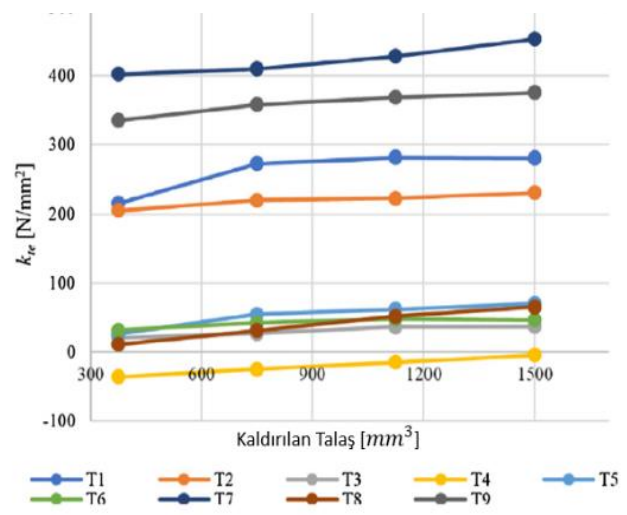

Şekil 4. $K_{t e}$ Artan aşınma oranına göre doğrusal yükselmesi [8]

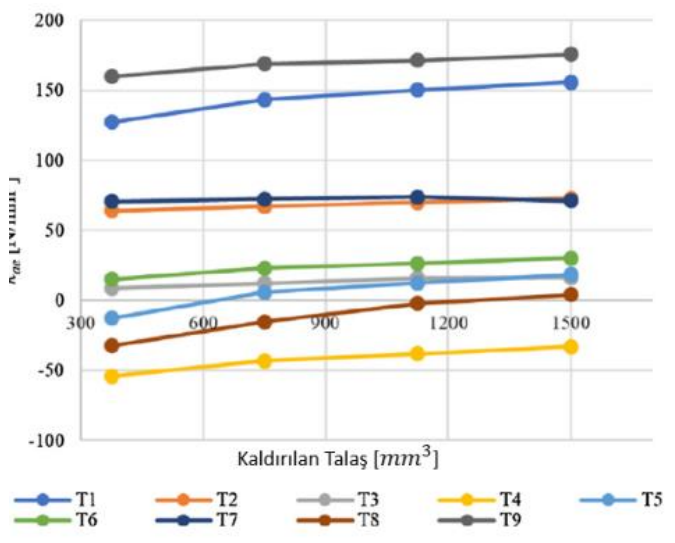

Şekil 5. $\mathrm{K}_{\mathrm{ae}}$ Artan aşınma oranına göre doğrusal yükselmesi [8] 


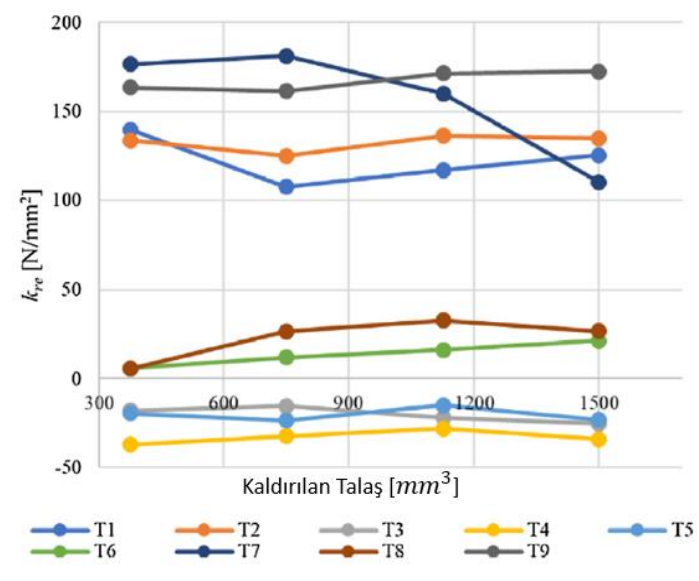

Şekil 6. Artan aşınma oranına göre $\mathrm{K}_{\mathrm{re}}$ süreklilik olmayan durumu [8]

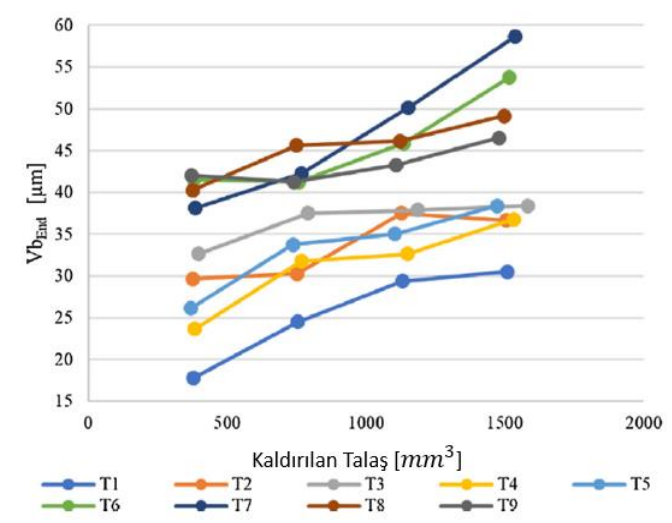

Şekil 7. Artan takım aşınması boyunca yanal aşınmanın gösterilmesi [8]

Şekil 4-5-6 da gösterilen değerlendirme sonuçları neticesinde takım aşınmasının, talaş kalınlığının artması ile işleme tabi tutulan bölgenin derinliği ile arttırdığ muştur [8].

Liu ve Ark yapmış oldukları çalışmada, titanyum alaşımları, uçak ve savunma sanayi üretiminde yaygın olarak kullanılmaktadır. Ancak, takım aşınması, kesilmesi zor malzemeler olarak bilinen titanyum alaşımlarının işlenmesi ciddi bir sorundur. Trokoidal frezeleme, kesilmesi zor malzemelerin yüksek verimli işlenmesi için umut verici bir teknolojidir. Titanyum alaşımını gerçekleştirmeyi amaçlayan bu makale, kuru trokoidal de deforme olmamış talaş kalınlığının takım aşınması ve talaş morfolojisi üzerindeki etkilerini araştırılmıştır. Deneylerde Tablo3'teki kesme parametreleri kullanılmıştır [2].
Tablo 3. Deneylerde kullanılan giriş parametreleri $\left(f_{\mathrm{z}}=0.1 \mathrm{~mm} / \mathrm{diş}\right.$ $a_{\mathrm{p}}=2 \mathrm{~mm}$ ) [2]

\begin{tabular}{ccccc} 
Test No. & $\begin{array}{c}\text { Kesme Hızı } \\
{[\mathrm{m} / \text { dak] }}\end{array}$ & $\begin{array}{c}\text { Kesme Derinliği } \boldsymbol{a}_{\boldsymbol{e}} \\
{[\mathrm{mm}]}\end{array}$ & $\begin{array}{c}\text { Kesme Devri } \\
{[\mathrm{rpm}]}\end{array}$ & $\begin{array}{c}\text { ilerleme Oranı } \\
{[\mathrm{mm} / \mathrm{dak}]}\end{array}$ \\
\hline 1 & & 0.2 & & \\
2 & 60 & 0.4 & 1592 & 637 \\
3 & & 0.6 & & \\
\hline 4 & \multirow{2}{*}{130} & 0.2 & & \\
5 & & 0.4 & 3448 & \\
6 & & 0.6 & & \\
\hline 7 & 200 & 0.2 & 5305 & \\
8 & & 0.4 & & \\
9 & & 0.6 & & \\
\hline
\end{tabular}

Her test için, takım aşınma durumu aşağıdaki kriterlere göre değerlendirilmiştir.

Ortalama yan takım aşınması $\mathrm{VB}=0,2 \mathrm{~mm}$;

Maksimum yan takım aşınması $\mathrm{VB}=0,3 \mathrm{~mm}$;

Aşırı Talaş aşınması ve takım kırılması

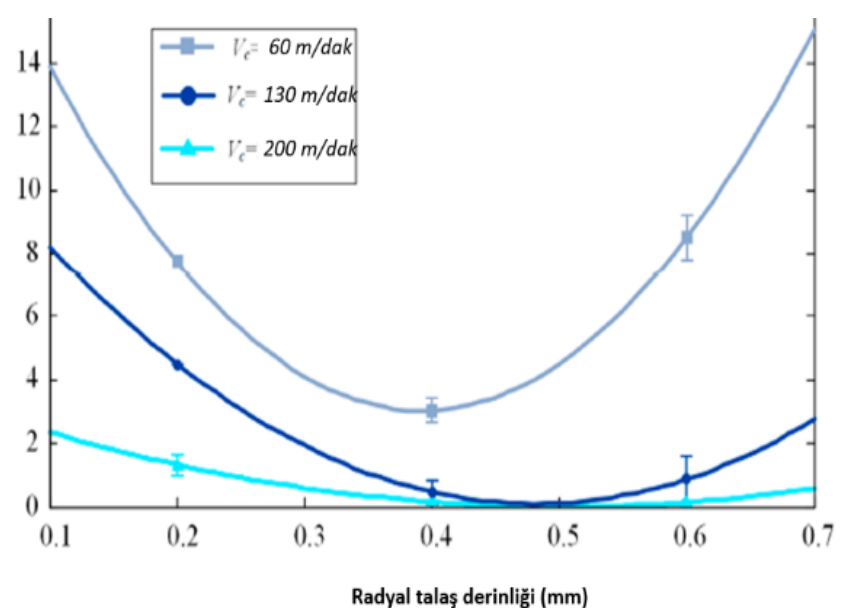

Şekil 8. Kaldırılan Talaş miktarı ve Talaş Derinliği [2]

Yapılan deneyler neticesinde Tablo 4 de Trokoidal frezeleme için çıkarılan malzemenin hacmine (VMR) dayalı radyal kesme derinliği ile ilgili bir takım aşınma modeli oluşturulmuş kesme hızı ve eksenel kesme derinliği açısından optimize edilmiş kesme parametreleri, azaltılmış takım yoluyla işleme verimliliğini artırmıştır. Şekil 8'de gösterilen deney sonuçları ve analizlerine dayanarak aşağıdaki sonuçlar çıkarılmıştır. Her kesme hızı, Vc $=60,130$ ve $200 \mathrm{~m} /$ dak için, frezelemede kaçınılması gereken en düşük VMR'ye karşılık gelen radyal bir kesme derinliği vardır. Bu araştırmada $0,4 \mathrm{~mm}$ radyal kesme derinliğinden kaçınılmalıdır. Malzemenin işlenmesinde kesme verimliliğini artırmak için uygun bir radyal kesme derinliği gereklidir. Bu makalede, $0,6 \mathrm{~mm}$ radyal kesme derinliği $60 \mathrm{~m} /$ dak kesme hızı ile birleştirilmiştir. Trokoidal frezeleme, titanyum alaşımı işlemek için umut verici bir yöntemdir. $0.6 \mathrm{~mm}$ radyal kesme derinliği ve $60 \mathrm{~m}$ / dak kesme hızı kullanarak, malzeme çıkarma hızı 1165.93 mm3 / dakikadır ve takım ömrü kuru Trokoidal 
frezelemede 177,5 dakikaya ulaşmıştır. Talaş morfolojisi takım durumu ile yakından ilişkilidir ve takım durumunu izlemek için talaş morfolojisi benimsenebilir [2].

Tablo 4. Test sonuçları VMR: Deneylerde Kaldırılan Talaş hacmi [2]

\begin{tabular}{cccc}
\hline Test No. & VMR $\left(\mathrm{mm}^{3}\right)$ & Efektif kesme Zamanı (s) & MRR $\left(\mathbf{m m}^{3} /\right.$ dakika) \\
\hline 1 & 77,280 & 18,198 & 254.8 \\
2 & 30,360 & 3575 & 509.6 \\
3 & 85,146 & 6683 & 764.4 \\
4 & 45,080 & 4904 & 551.6 \\
5 & 4692 & 255 & 1103.2 \\
6 & 8786 & 319 & 1654.8 \\
7 & 13,340 & 943 & 848.8 \\
8 & 1472 & 52 & 1697.6 \\
9 & 1518 & 36 & 2546.4 \\
\hline
\end{tabular}

Shixiong ve Ark yapmış oldukları çalışmada, bir kalıp cebinin yüksek hızlı frezeleme esnasında işlerken, kesilecek alanda daha yüksek miktarda malzemenin bulunması nedeniyle cebin dar alanı veya köşesindeki takım yükü keskin bir şekilde artabilir. Bu makalede işleme kuvveti, işleme takımı ve cep geometrisini dikkate alan bir Trokoidal işleme yöntemi önerilmiştir. İlk olarak, Trokoidal işlemede giriş açısının geometrik modellemesi için bir yöntem önerilmektedir. Yapılan çalışmada $6 \mathrm{~mm}$ çapında Alüminyum Titanyum Nitrür kaplı (TiAlN) Düz parmak freze takımı seçilmiştir. Malzeme: P20 HRC 36 diş başına ilerleme $f_{z}=0.03 \mathrm{~mm} /$ diş İş mili devri 8000 devir/dak Talaş kesme derinliği Ap=4mm olarak belirlenmiştir. İşleme Yöntemi olarak Kontur ve Trokoidal işleme olarak işlem yapılmıştır. Şekil 9'da gösterilmiştir.

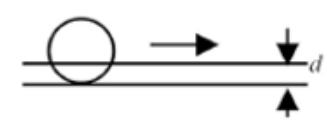

Kontur Paralel İşleme

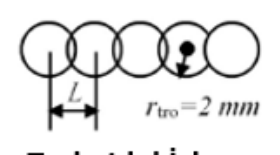

Trokoidal İşleme
Şekil 9. İki model seti L-d karşılaştırması [5]

Frezeleme kuvvetinin maksimum ve ortalama değerleri analiz edilmiş, Trokoidal işleme prosesi sırasında kesme kuvveti eğrisi ile giriş açısı eğrisi arasındaki ilişkiler araştırılmıştır. Trokoidal işleme ile ilgili temel deneylere dayanarak, kesme kuvveti ve takım aşınması için sonuçlar elde edilmiştir. Bu çalışmada, Trokoidal frezeleme için uygun bir kontrol stratejisi önerilmektedir. Trokoidal işleme için bu kontrol stratejisine dayanarak, optimizasyon çalışmaları yapılmıştır. Son olarak, cep boşaltma işlemesinde karşılaştırma deneyleri yapılmış, ilerleme hızı ayarlama yöntemiyle karşılaştıııldığında, Trokoidal işlemede kesme kuvvetinin köşelerde ve dar yuvalarda takım aşınması üzerinde daha iyi kontrol sağladığı ispatlanmıştır. Bu yöntemle kesme kuvveti ve işleme titreşimleri daha küçük olduğu ve takım aşınması önemli ölçüde azalttığı ispatlanmıştır. İlgili sonuç grafiği Şekil 10-11' deki grafikte görülmektedir [5].

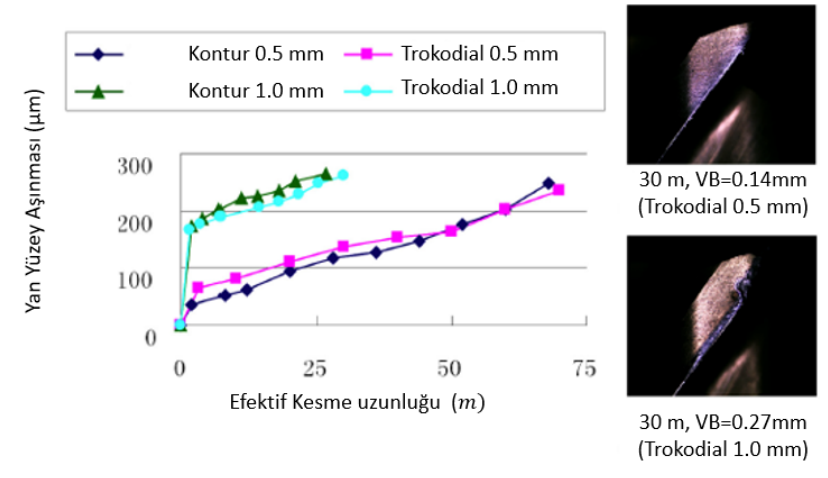

Şekil 10. Cep işlemede iki modelde yan yüzey aşınmasının karşılaştırılması [5]

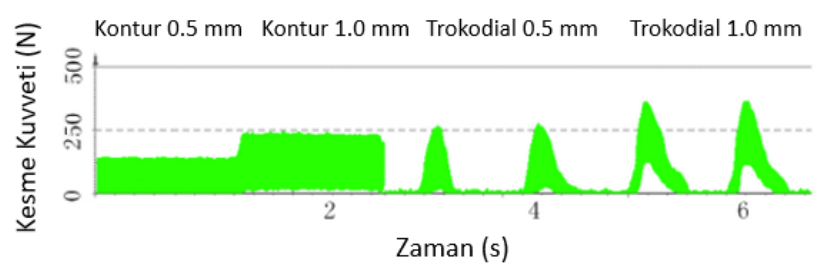

Şekil 11. Cep işlemede iki modelde kesme kuvvetinin karşılaştırılması [5]

Mithilesh ve ark. yapmış oldukları çalışmada, takım tezgahlarında meydana gelen titreşimleri incelemiş ve stabilite ve kararsız bölgeleri sıfırıncı dereceden yaklaşık yöntemi ile tanımlamak için iki serbestlik dereceli sistem için Stabilite Lob Diyagramı (SLD) geliştirmiş ve tahmin edilmiştir. Dinamik kesme kuvveti modeli, rejeneratif kesilmemiş talaş kalınlığı kullanılarak teğetsel ve radyal yönlerde modellenmiştir. Kesilmemiş talaş kalınlığı, takımın kesici kenarı tarafindan izlenen Trokoidal yol kullanılarak modellenmiştir. Dinamik kesme kuvveti katsayıları ortalama kuvvet yöntemine göre belirlenmiştir. Dinamik kesme kuvveti katsayılarını belirlemek için farklı ilerleme hızlarında ve eksenel kesme derinliklerinde çeşitli deneyler yapılmış ve SLD'yi tahmin etmek için kullanılmıştır. Geliştirilen SLD'nin fizibilitesini ve etkinliğini doğrulamak için birkaç başka deney yapılmıştır. Önerilen yöntemin SLD'nin öngörülmesinde oldukça etkili 
olduğu bulunmuştur. Kararlı ve dengesiz kesme bölgesindeki kesme kuvvetleri deneysel kesme kuvvetleri ile uyumludur. Çıkan sonuçlar neticesinde Küresel uç ile frezeleme iş mili hızı arttıkça stabilite bölgesinin açıklığı artar. SLD değerlerinin düşük dönme hızında dengesiz olabileceği ve aynı kesme derinliğinde ( 0.2 ila $1.8 \mathrm{~mm}$ arasında) dönme h1zının artırılması ile dengeli stabil olacağı gözlenmiştir. Tırlama için stabilite şemasını doğrulamak için farklı derinliklilerde doğrulama testi yapılmıştır. Yüksek hızda küresel frezeleme işleminde, tırlama uygun bir iş mili hızı ve buna karşılık gelen eksenel kesme derinliklerinde simule edilerek daha yüksek işleme verimliliği elde edilebilir. Geliştirilen kesilmemiş talaş kalınlığ kuvveti katsayılarının belirlenmesi hızlı ve hassastır. Teğetsel ve radyal yönlerdeki kesme kuvvetleri, Kesici takımın kesici kenarı tarafindan hareket ettirilen trokoidal yol kullanılarak kesin olarak belirlenmiştir. Teğetsel ve radyal yönlerde simule edilmiş ve deneysel kesme kuvvetlerinin birbirine çok yakın olduğu bulunmuştur. Bununla ilgili sonuçlar Şekil'12 de görülmektedir. Kararlı bölgedeki kesme kuvvetleri, teğet ve radyal yönlerde sırasıyla maksimum $\% 2,76$ ve \%11,69 sapmalara sahipken, kararsız bölgedeki yukarıdaki kuvvetler için $\% 5$ ’ten daha az sapma vardır [9].

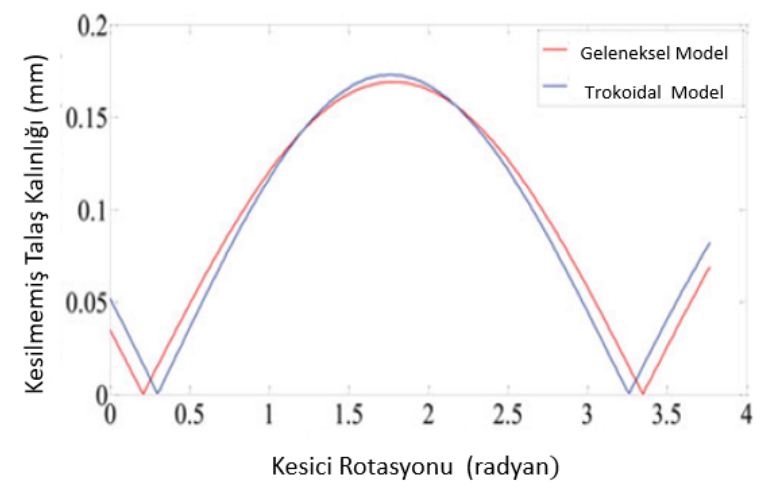

Şekil 12. Geleneksel ve trokoidal model için kesilmemiş talaş kalınlığının $\mathrm{R}=5 \mathrm{~mm}$, eksenel kesme derinliği $=1.8 \mathrm{~mm}$ ve ilerleme hızı $=0.22 \mathrm{~mm} /$ diş karşılaştırılması [9]

Yanjie ve ark. yapmış oldukları çalışmada, Kesme kuvvetlerinin doğru modellenmesi ve tahmini, mikro uç frezeleme prosesinde proses planlama ve optimizasyon için önemlidir. Kesme kuvvetlerini tam olarak tahmin etmek için, takım ucunun kesim trokoidal yörüngesinin ve daha önce geçen tüm dişlerin, yörünge çıkışının, minimum talaş kalınlığının ve malzemelerin kesme yörüngesinin kombinasyonu dikkate alınarak yenilikçi bir kesilmemiş talaş kalınlığı algoritması önerilmektedir. Önerilen kesilmemiş talaş kalınlığı algoritması, takımın tükenmesinin neden olduğu giriş ve çıkış açılarının varyasyonunu da göz önünde bulundurur. Kesme kuvveti katsayılarını belirlemek için, gerinim sertleşmesini, gerinim hızı hassasiyetini, ısıl yumuşatma davranışını ve sıcaklığa bağlı akışı dikkate alan dik mikro kesmenin sonlu bir eleman modeli (FEM) oluşturulmuştur.

FEM analizinin sonuçlarına dayanarak, kesme kuvveti katsayıları doğrusal olmayan bir denklem ile tanımlanır ve temsil edilir. Kesilmemiş talaş kalınlı̆̆ı, kesici kenar yarıçapı ve kesme hizı kullanılarak belirlenen kesme kuvveti katsayıları mekanik bir kesme kuvveti modeline entegre edilmiş ve mikro uç frezeleme kuvvetlerini simule etmek için kullanılmıştı. Simülasyon sonuçları, deney sonuçları ile çok tatmin edici bir uyum göstermektedir. Simülasyon sonuçlarına dayanarak, kesme kuvveti katsayıları, kesilmemiş talaş kalınlığı, kesici kenar yarıçapları ve kesme hızlarının doğrusal olmayan fonksiyonları olarak tanımlanır. Ayrıca, salgı ve takım kenarı yarıçapının etkisini dikkate alan etkili eğim açısı hesaplanmış ve kesme kuvveti modeline dahil edilmiştir. Önerilen modeli kullanarak öngörülen kuvvetler deneysel sonuçlarla doğrulanmıştır. Öngörülen ve deneysel kesme kuvvetleri benzer varyasyonları birbirine yakın genlik seviyeleri gösterir. İncelenen üç farklı kesme koşulunun simülasyonları ve filtrelenmiş deneysel maksimum kesme kuvvetleri arasındaki fark\%7'den az olduğu görülmüştür [10].

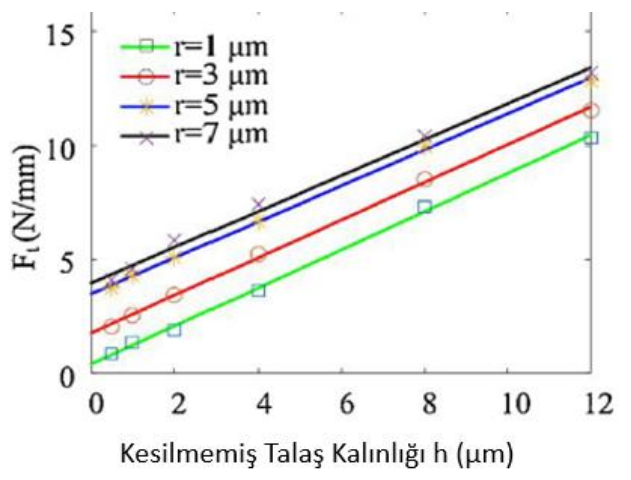

(a) Kesme Yönü

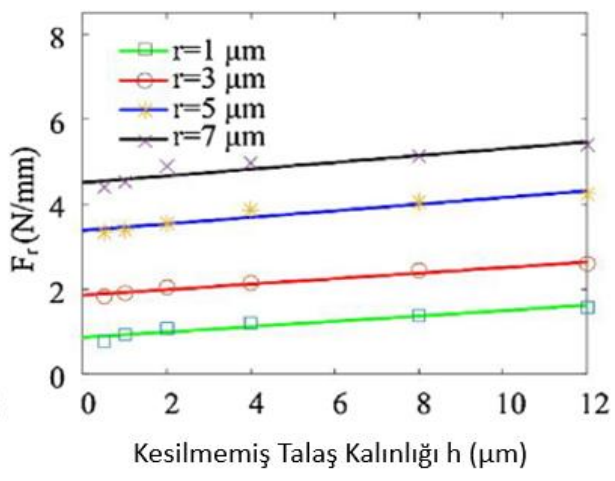

(a) İlerleme Yönü

Şekil 13. Farklı kesme çaplarında elde edilen kesme kuvvetlerinin gösterilmesi 10] 
Sahoo ve Ark. yapmış oldukları çalışmada, mikro uç frezelemede kesme kuvvetlerinin tahmini hem işleme yüzeyinin kalitesi hem de takımın güvenliği için önemli bir husustur. Ayrıca, kesme katsayılarının tahmini, gerçek kesme kuvvetlerinin kesin tahmini için çok önemlidir. Genel olarak, bunlar çok fazla enerji ve kaynak tüketen kalibrasyon deneylerinin kesilmesiyle elde edilir. $\mathrm{Bu}$ nedenle, bu tür engelleri aşmak ve tamamen analitik bir modelleme yapmak için, bu çalışma titanyum alaşımı Ti6Al-4V'nin mikro uç frezelemesinde kesme kuvvetlerinin tahmini için hibrit bir yaklaşım önermektedir. Öncelikle kesme kuvveti katsayıları, Ti-6Al-4V'nin yuvarlak kenarlı karbür takımı kullanılarak dik kesim modeli dikkate alınarak sonlu eleman simülasyonu kullanılarak değerlendirilmiştir. Johnson-Cook malzeme modeli, sonlu elemanlar (FE) analizinde akış gerilimi hesaplaması için düşünülmüştür. Kesme kuvveti katsayıları, bir dizi deforme edilmemiş talaş kalınlığı (UCT) için kesme işlemi simule edilerek çıkarılmıştır. Son olarak, çıkarılan kesme kuvveti katsayıları dahil edilerek küçük element kesme kuvveti entegre edilerek mekanik kesme kuvveti modeli geliştirilmiştir. Takım merkezinin hem düşük hem de yüksek değeri tükenmek için kullanılabilecek gelişmiş bir UCT algoritması, takım merkezinin trokoidal yörüngesi, takım tükenmesi, minimum talaş kalınlığ 1 ve elastik davranışı ve önceki dişlerin tek bir devir için yörüngeleri dikkate alınarak uygulanmıştır. Takım için önerilen modeli doğrulamak için kesme kuvveti deneyleri yapılmış ve sonuçlar karşılaştırılmıştır. Karşılaştırmalı bir analiz, öngörülen ve deneysel kesme kuvvetleri arasında çok iyi bir uyum olduğunu göstermiştir [11].

Rauch ve Ark yapmış oldukları çalışmada, trokoidal takım yolları uygulanması için çeşitli iyileştirmeler önerilmiştir. İlk olarak, takım yolu parametrelendirilmesine göre maksimum radyal kesme derinliği hesaplaması yapılır. İki enterpolasyon modeli test edilir ve karşılaştırılır. Amaç, proses kısıtlamalarına göre en iyi takım yolu parametrelerini seçmektir. Ardından, cep frezeleme uygulamaları için geliştirilmiş takım yolu üretimi önerilmektedir. Cep Freze uygulamaların için önerilen yaklaşımı doğrulamak ve trokoidal takım yolu uygulamasının etkinliğini araştırmak için deneysel bir çalışma yapılmıştır. Burada sunulan çalışma, sonuç olarak trokoidal takım yolunun uygulanmasının geliştirilmesine yol açarak işleme süresinin kısaltmasına yönelik bir yaklaşım göstermiştir. Bu yazıda, trokoidal frezelemenin; trokoidal parametrelerin seçimi ve CNC takım tezgahlarında trokoidal takım yollarının uygulanması olmak üzere, iki yönü incelenmiştir. Deneylerde kullanılan giriş parametreler Tablo 5 de gösterilmiştir.
Tablo 5. Deneylerde kullanılan giriş parametreleri [1]

\begin{tabular}{|c|c|c|c|c|c|}
\hline Trokoid & dal Radius (mm) & Kesme Hlzl (m/dak) & Ilerleme Oranı (mm/dişs) & Trokoidal Adm (mm) & Talaş kaldirma Derinligïi $(\mathrm{mm})$ \\
\hline Trokoidal 1 & 10 & 2400 & 0.35 & 8 & 6.66 \\
\hline Trokoidal2 & 10 & 2400 & 0.35 & 2 & 13.50 \\
\hline
\end{tabular}

Önerilen gelişmeler ışı̆̆ında tam daldırma yapılandırmasından kaçınılmasına yol açmaktadır. Takım hareketleri işlenen malzemenin özellikleri ve durumuna göre (cep yuva vb.) değişmektedir. Takım hareketleri işleme yönü boyunca ilerleme hızında artış olması devamlı olarak devam etmektedir. Ayrıca, radyal kesme derinliği hesaplama algoritması sayesinde hem işleme sürelerini iyileştirmek hem de teknolojik kısıtlamaları karşılamak için trokoidal model parametrelendirilmiştir. Bu çalışma ile NC takım tezgahlarında trokoidal takım yolları uygulaması önerilen yaklaşımı doğrular ve üretim ortalamasıyla ilişkili gereksinimleri karşılaştırlmıştır. İlgili deney sonuçları Şekil 15-16 da gösterilmiştir.
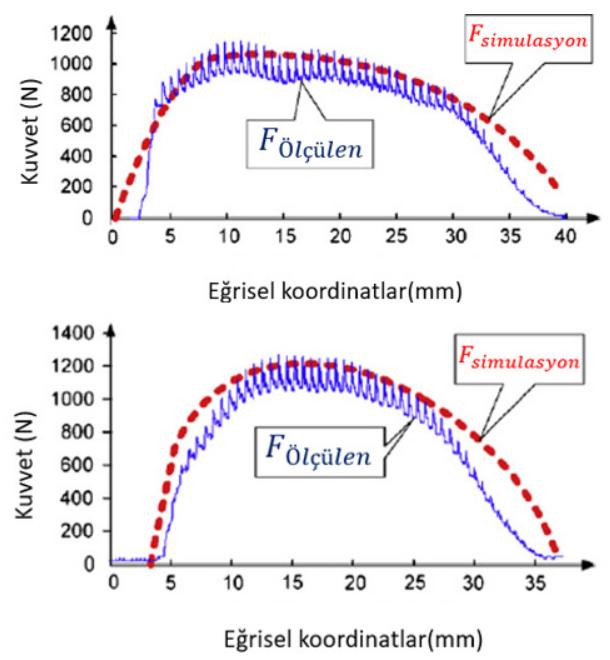

Şekil 15. Ölçülen ve simule edilen ortalama kuvvetlerin karşılaştırılması [1]

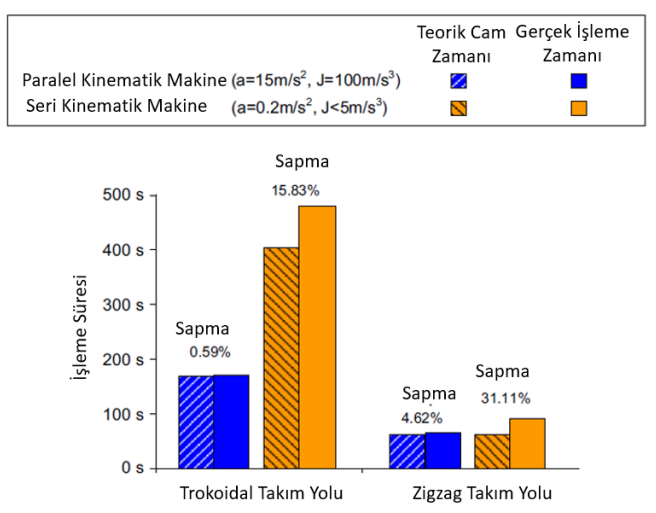

Şekil 16. Teorik ve gerçek işleme süreleri arasındaki sapmalara göre iki takım tezgahının karşılaştırılması.[1] 
Bu nedenle, mevcut yüksek hızlı üretim bağlamında, trokoidal takım yollarının bu ayrıntılı çalışması CAM uzmanlarına ve NC programcıları, mevcut takımların yeteneklerine ve parçanın makineye göre en uygun işleme stratejisini oluşturmalidir [1].

Hui ve Ark yapmış oldukları çalışmada, karmaşık cep işleme için yeni bir adaptif trokoidal (TR) takım modeli önermiştir. Önerilen model TR yarıçapını ayarlayabilirken, aynı anda her takım yolu döngüsünün üretimi için uyarlanabilir trokoidal bir adım sunar. Değişen yarıçap ile, karmaşık bölgeler tek bir TR takım yolu ile işlenebilir. Ayrıca, her TR döngüsünün adımı, sabit radyal kesim derinliğini korumak için çeşitli yarıçapa referans alınarak ayarlanabilir ve dolayısıyla tüm TR döngüleri arasında daha istikrarlı malzeme kaldırma oranı elde edilebilir. Karmaşık iç ve dış sınırlara sahip cep boşaltmak için, deneysel çalışmada önerilen TR takım yolunun kesme kuvvetlerinin dalgalanmasını etkili bir şekilde en aza indirebileceğini ve daha iyi takım verimliliği elde edebileceğini göstermiştir[12].

Li ve Ark yapmış oldukları çalışmada, kanal işlemi üretimde de yaygın olarak kullanılan bir işleme şeklidir. Trokoidal frezeleme, azaltılmış kesme kuvveti yükü ve daha iyi 1sı dağılımı sayesinde, kesici takım ömrünü önemli ölçüde uzatmaya yardımcı olduğundan kanal işlemek için iyi bir stratejidir. Bununla birlikte, trokoidal frezeleme, geleneksel dairesel frezeleme ye göre toplam işleme süresi, talaş kaldırma oranı tarafından daha üstündür. Bu makalede kavisli bir sınıra ve değişen genişliğe sahip rasgele karmaşık yeni bir trokoidal desen türü önerilmektedir. İşenecek kanal için, toplam işleme süresini en aza indirme amacı için 1sı dağıl1mını ve kesme kuvvetini ölçerek en iyi trokoidal takım yolunu bularak optimizasyon gerçekleştirilmiştir. Bu çalışma hem bilgisayar simülasyonlarında hem de fiziksel kesme deneylerinde gerçekleştirilmiş ve sonuçlar değerlendirildiğinde önerilen yeni tip trokoidal takım yolu model türünün geleneksel dairesel tipe göre amaçlanan avantajları doğrulamıştır [3].

Pleta ve Ark yapmış oldukları çalışmada, takım yolu teknikleri arasında kesme parametreleri ve katsayı değerleri hakkında bir anlayış oluşturmak amacıyla trokoidal frezeleme için kesme kuvveti katsayılarının toplanması araştırılmıştır. Yazarlar tarafından önerilen yeni bir talaş kalınlığı modeli kullanımı daha önceki bir çalışmada trokoidal frezeleme için kesme kuvveti katsayıları toplanmıştır. Trokoidal kuvvet modelleri için kanal açmada toplanan kesme kuvveti katsayılarının uygulanabilirliğini daha iyi anlamak için bu çalışmada, ikisi trokoidal frezeleme konfigürasyonunda ve beş kanal işleme konfigürasyonunda olmak üzere toplam yedi deney tasarımı gerçekleştirilmiştir. Sonuç olarak, trokoidal frezelemede kesme kuvveti modellemesinin, literatürde yaygın olan kanal açma testlerinden değil, trokoidal frezeleme testlerinden toplanan kuvvet katsayılarını kullanması gerektiği sonucuna varılmıştır. Kanal açma ve trokoidal koşullar arasında diş başına ilerlemeyi eşleştirerek, Teğetsel kesme kuvveti katsayılarının tahmininin talaş kalınlığı geometrilerine dayanan eşleşen işleme parametrelerine kıyasla doğru olduğu bulunmuştur [13].

Zagorski ve Ark yapmış oldukları çalışmada, kesme hızı vc ve trokoidal adım modifikasyonunun seçilen işlenebilirlik parametreleri (kesme kuvveti bileşenleri ve titreşim) üzerindeki etkisini araştırmak için hazırlanmıştır. Ayrıca, daha ayrıntılı bir analiz için, seçilen yüzey pürüzlülüğü parametreleri araştırılmıştır. Araştırma, iki dereceli magnezyum alaşımları (AZ91D ve AZ31) için gerçekleştirildi ve kararlı işleme parametrelerini belirlemeyi ve frezeleme işleminin dinamiklerini, yani kesme kuvveti bileşenlerinde ve titreşimde meydana gelen değişimi araştırmayı amaçlamıştır. Testlerin belirtilen kesme parametreleri aralığ1: vc $=400$ $1200 \mathrm{~m} /$ dak ve str $=\% 5-30$. Sonuçlar, kesme veri modifikasyonunun inceleme altındaki parametre üzerinde önemli bir etkisi olduğunu göstermektedir; Vc'deki (kesme hızı) artış, kesme kuvveti bileşenlerinin azalması ile sonuçlanmıştır. Ve seçilen kesme parametreleri, testlerde kaydedilen titreşim seviyesi Yapay Sinir Ağları (Radyal Temel Fonksiyon ve Çok Katmanlı Algılayıcı) ile modellenmiştir. Sinir ağlarının magnezyum alaşımlarının frezelemesinde kesme kuvvetinin ve titreşimin tahmin edilmesi için bir araç olarak uygunluğunu doğrulanmıştır [14].

Akhavan ve Ark yapmış oldukları çalışmada, Trokoidal frezeleme, takım aşınması başına malzeme kaldırma oranını artırarak malzeme kesme enerjisini azaltır ve takım performansını iyileştirirken verimlilik maliyetiyle birlikte alternatif bir yol planlama stratejisi olarak ön plana çıkmaktadır. Takımın düşük radyal kesme kuvvetlerine ek olarak, trokoidal frezelemenin nikel bazlı süper alaşımlar gibi zor kesilen alaşımların işlenmesinde arzu edilen bir takım yolu olmasını sağlamıştır. $\mathrm{Bu}$ çalışmanın amacı, trokoidal frezelemenin dinamik stabilitesini incelemek ve IN718 süper alaşımını işlerken takım yolu parametrelerinin stabilite davranışı ile etkileşimini araştırmaktır. Dairesel frezeleme dinamiği (trokoidal frezeleme için bir takım yolu) ile ilgili yayınlanmış birkaç çalışma olsa da bu çalışma gerçek trokoidal takım yolunun dinamiklerini ele almaktadır. İlk olarak, talaş geometrisi niceleme stratejisi açıklanmıştır, daha sonra trokoidal frezelemede tırlama karakteristik denklemi formüle edilip tırlama stabilite lobları diyagramı ile izlenmiştir. Kesim sırasında talaş geometrisinin sabit kaldığı geleneksel bir uç frezeleme işleminden farklı olarak (stabilite bölgesini temsil eden tek bir tırlama diyagramı ile sonuçlanır), trokoidal frezeleme tırlama diyagramları her bir talaş 
geometrisindeki değişiklik (artı kesici giriş ve çıkış açıları) ile zaman içinde gelişecektir. Kritik kesme derinliğinin sınırı geleneksel uç frezeleme ile karşılatırken stabilite korunurken kesme derinliğinin on kata kadar artırllabileceği gösterilmiştir. Son olarak, kesme takımının yer değiştirme yanıtı, sabit ve kararsız kesme bölgeleri için zaman alanında simule edilmiş; sayısal benzetim ve teorik sonuçlar karşılaştırılmıştır [4].

\section{SONUÇLAR VE DEĞERLENDİRME}

Yapılan çalışmalarda kuvvet modellemesinin temelinin, kesme kuvveti katsayıları ve kenar kuvvet katsayıları ile birlikte kesilmemiş talaş kalınlığı modellemesinde yatmaktadır [8]. Trokoidal frezelemede kesme kuvveti modellemesinin, literatürde yaygın olan kanal açma testlerinden değil, trokoidal frezeleme testlerinden toplanan kuvvet katsayılarını kullanması gerektiği sonucuna varılmıştır [13]. Ayrıca, her trokoidal döngüsünün adımı, sabit radyal kesim derinliğini korumak için çeşitli yarıçapa referans alınarak ayarlanabilir ve dolay1sıyla tüm trokoidal döngüleri arasında daha istikrarlı malzeme kaldırma oranı elde edilebilir. Karmaşık iç ve dış sınırlara sahip cep boşaltmak için, deneysel çalışmada önerilen trokoidal takım yolunun kesme kuvvetlerinin dalgalanmasını etkili bir şekilde en aza indirebileceğini ve daha iyi takım verimliliği elde edebileceğini göstermiş̧ir [12].Takım aşınmasının, talaş kalınlığının artması ile işleme tabi tutulan bölgenin derinliği ile arttırdığ 1 bulunmuştur [8]. Talaş morfolojisi takım durumu ile yakından ilişkilidir ve takım durumunu izlemek için talaş morfolojisi benimsenebilir [2]. Talaş kaldırma sürecinde, izlenmeyen takım aşınması parça bozukluğunu ve hurda sayısını artırmakla beraber, aynı zamanda takımın kırılmasına ve pahalı CNC takım tezgâhlarında yüksek hasarlara sebep olmaktadır [15]. Bu çalışmalardan anlaşılacağı üzere takım aşınması; kesme parametreleri, takım açılarına ve işleme durumuna bağlı olduğu ispatlamıştır. Ayrıca takım aşınması ve kesme parametreleriyle ile ortaya çıkan tırlama davranışı izlemekte önemlidir. İşleme verimliliğini artırmak ve üretim kalitesini sağlamak için tırlamalardan kaçınılmalıdır [16]. Yapılan literatür çalışmalarında küresel uç ile frezelemede iş mili hızı arttıkça stabilite bölgesinin açıklığı artar. SLD değerlerinin düşük dönme hızında dengesiz olabileceği ve aynı kesme derinliğinde dönme hızının artırılması ile dengeli stabil olacağı gözlenmiştir [9]. Ayrıca trokoidal frezelemede kritik kesme derinliğinin sınırı geleneksel uç frezeleme ile karşılatırken stabilite korunurken kesme derinliğinin on kata kadar artırılabileceği gösterilmiştir [4].

\section{KAYNAKLAR}

[1] M. Rauch, E. Duc, ve J. Hascoet .(2009). Improving trochoidal tool paths generation and implementation using process constraints modelling. International Journal of Machine Tools \& Manufacture" c. 49, ss. 375-383

[2] Dongsheng L,Zhang Y.,Luo M.,Zhang D. (2019).Investigation of Tool Wear and Chip Morphology in Dry Trochoidal Milling of Titanium Alloy Ti-6Al-4V.Materials c12, s1937

[3] Li Z., Xu K., ve Tang K.(2019). A new trochoidal pattern for slotting operation. The International Journal of Advanced Manufacturing Technology c102:s1153-1163

[4] Niaki F., Pleta A., Mears L. Potthoff N. Bergmann J. Wiederkehr P. (2019). Trochoidal milling: investigation of dynamic stability and time domain simulation in an alternative path planning strategy. The International Journal of Advanced Manufacturing Technology c102:s1405-1419

[5] Shixiong W., Wei M., Bin L., Chengyong W. (2016). Trochoidal machining for the high-speed milling of pockets. Journal of Materials Processing Technology c233:s29-43.

[6] Bastekeli E.(2019).Trokoidal Frezelemede İşlem Parametrelerinin Etkisinin İncelenmesi.Yüksek Lisans Tezi, Yıldız Teknik üniversitesi Türkiye

[7] Özkan M. (2010). Bilgisayar Destekli İmalatta Dalarak Kaba ve Trokoidal İşleme Algoritmalarının Birleştirilmesi. Yüksek Lisans Tezi, Yıldız Teknik üniversitesi Türkiye

[8] Pleta A., Nithyanand G.,Niaki F.,Mears L. (2019). Identification of optimal machining parameters in trochoidal milling of Inconel 718 for minimal force and tool wear and investigation of corresponding effects on machining affected zone depth. Journal of Manufacturing Processes" c43 s54-62

[9] Dikshit M.,Puri A.,Maity A. (2017). Chatter and dynamic cutting force prediction in high-speed ball end milling. Machlning Sclence and Technology c2 ss291-312

[10] Yuan Y.,Jing X.,Ehmann K.,Cao J.,Li H. (2018). Modeling of cutting forces in micro end-milling. Journal of Manufacturing Process c 31 s $844-858$

[11] Sahoo P.,Pratap T.,Patra K. (2018). A hybrid modelling approach towards prediction of cutting forces in micro end milling of Ti-6Al-4V titanium alloy. International Journal of Mechanical Sciences, c. 150 ss. 495-509

[12] Wang Q.,Wang S.,Jiang F.Li J.,(2016). Adaptive trochoidal toolpath for complex pockets machining. International Journal of Production Research Vol 54 c.20 ss 5976-5989

[13] Pleta A.,Niaki F.,Mears L. (2018). A comparative study on the cutting force coefficient identification. 46th SME North American Manufacturing Research Conference c.26 ss.570-579

[14] Zagórski I., Kulisz M., Kłonica M., Matuszak J. (2019). Trochoidal Milling and Neural Networks Simulation of Magnesium Alloys. Materials c. 12 ss. 2070

[15] Salımıasl A.,Rafighı M.(2017). Titreşim ve Kesme Kuvveti Esaslı Takım Aşınmasının Bulanık Mantıkla İzlenmesi ve Tahmini. Politeknik Dergisi, 2017; c.20 (1) ss.111-120

[16] Zhang J., Liu C.,(2019). Chatter stability prediction of ballend milling considering multi-mode regenerations. The International Journal of Advanced Manufacturing Technology c.100 ss.131-142 